\title{
Preparation of Stellerite Loading Titanium Dioxide Photocatalyst and Its Catalytic Performance on Methyl Orange
}

\author{
Hua Chen, ${ }^{1,2,3}$ Jianhua Wang, ${ }^{1}$ Huajun Wang, ${ }^{1}$ Fei Yang, ${ }^{2}$ Jia-nan Zhou, ${ }^{3}$ Jiajun Fu, ${ }^{3}$ \\ Jie Yang, ${ }^{3}$ Zheng Yuan, ${ }^{3}$ and Bingbing Zheng ${ }^{3}$ \\ ${ }^{1}$ Zhejiang Yongtai Paper Co. Ltd., Hangzhou 311421, China \\ ${ }^{2}$ State Key Lab of Pulp and Paper Engineering, South China University of Technology, Guangzhou 510640, China \\ ${ }^{3}$ Zhejiang Provincial Key Lab for Chem \& Bio Processing Technology of Farm Product, School of Light Industry, \\ Zhejiang University of Science and Technology, Hangzhou 310023, China
}

Correspondence should be addressed to Fei Yang; 7008774@qq.com

Received 7 October 2015; Accepted 11 November 2015

Academic Editor: Bao Yu Xia

Copyright (C) 2015 Hua Chen et al. This is an open access article distributed under the Creative Commons Attribution License, which permits unrestricted use, distribution, and reproduction in any medium, provided the original work is properly cited.

\begin{abstract}
$\mathrm{TiO}_{2}$ /stellerite composite photocatalysts were prepared by dispersing $\mathrm{TiO}_{2}$ onto the surface of $\mathrm{HCl}, \mathrm{NaOH}$, or $\mathrm{NaCl}$ treated stellerite using a sol-gel method. The materials were characterized by scanning electron microscopy (SEM), energy dispersive X-ray (EDX), Fourier transform infrared spectroscopy (FT-IR), BET surface area analysis, and X-ray diffraction (XRD). $\mathrm{HCl}$ and $\mathrm{NaCl}$ modification result in the promotion of the pore formation at the stellerite surfaces and induced the microscopic changes, while the surface morphology and structure of the stellerite were almost ruined by $\mathrm{NaOH}$ modification. Supported $\mathrm{TiO}_{2}$ calcinated at $200^{\circ} \mathrm{C}$ presented anatase structure. The photocatalytic degradation activities of $\mathrm{TiO}_{2}$ loaded $\mathrm{HCl}$ and $\mathrm{NaCl}$ modified stellerite were better than that of natural stellerite, accompanied with increasing specific surface area. On the contrary, $\mathrm{NaOH}$ modification induced the loss of photocatalytic ability of composite due to the generation of silicates.
\end{abstract}

\section{Introduction}

In recent years, with the rapid development of China's economy, the industry has achieved a rapid development. However, the environmental impact should not be overlooked. For example, the amount of discharge of papermaking wastewater amounted to 2.855 billion tons in 2013, accounting for $14.9 \%$ of total industrial wastewater.

The traditional industrial wastewater treatment included physical chemistry and biochemical methods [1,2]. However, the adsorbable organic halogens (AOX) in wastewater cannot be effectively treated by those methods. It was reported that AOX can be decomposed by enzyme treatment, but the technique is still at the experimental stage because of high costs, considerable treatment time, and lack of substrates [3].

In recent years, titanium dioxide catalyst is generally applied for treating wastewater containing organic contaminants due to its excellent ability to achieve complete mineralization of the organic contaminants under moderate conditions such as ambient temperature and ambient pressure $[4,5] . \mathrm{TiO}_{2}$ photocatalytic degradation of a cellulose ECF effluent was evaluated by Pérez et al. [6]. It was found that after $30 \mathrm{~min}$ of reaction more than $60 \%$ of the toxicity was removed and after 420 min of reaction none of the initial chlorinated low molecular weight compounds were detected, suggesting an extensive mineralization which was corroborated by 95 and 50\% AOX and TOC removals, respectively.

However, the difficulties of the nano $\mathrm{TiO}_{2}$ particle's fixation and recovery due to its small diameter seriously impede its industrialization, so the supported problem has become a hot research topic in $\mathrm{TiO}_{2}$ photocatalysis domain at present.

Recent research has investigated many kinds of supports for dispersing $\mathrm{TiO}_{2}$ : zeolite [7], glass [8], stainless steel [9], carbon nanotube [10], and graphene [11] are some very recent examples reported in the literature. 
Among these materials, zeolites are attractive candidates due to their uniform pores and channel sizes, huge surface area, high adsorption capacity, and low cost. However, the adsorption ability of natural zeolite to pollutants is very limited because the channels and cavities of the zeolite structure were blocked. In order to improve the absorption and exchange capacities and pollution treatment capabilities of zeolite, many attempts have been made such as ion exchange, organic modification, and calcination modification. Among them, the ion exchange modification method becomes the research focus because of its convenient operation, pollution, and environmental friendliness.

In this study, we are concerned with the photocatalytic decomposition of methyl orange (MO) over $\mathrm{TiO}_{2}$ composite nanophotocatalyst prepared by dispersing $\mathrm{TiO}_{2}$ on the surface of modified stellerite. The structure, crystal phase, morphology, BET surface area, and photocatalytic activity of the prepared photocatalyst were also investigated.

\section{Experimental}

\subsection{Materials}

2.1.1. Modified of Stellerite. Stellerite was obtained from Jinshansida Co. Ltd. (Guangxi, China). Chemical composition of the zeolite is $\left(\mathrm{K}_{0.017} \mathrm{Na}_{0.042} \mathrm{Ca}_{1.13}\right)_{1.189}\left[\mathrm{Al}_{1.997} \mathrm{Si}_{7.05}\right.$ $\left.\mathrm{O}_{18}\right] \cdot 6.75 \mathrm{H}_{2} \mathrm{O}$. The stellerite was washed repeatedly by distilled water in order to remove some impurity ions and then was dehydrated in an oven box at $100^{\circ} \mathrm{C}$ for $12 \mathrm{~h} .7 .5 \mathrm{~g}$ of stellerite was put into a round flask containing $75 \mathrm{~mL}$ different concentrations of $\mathrm{HCl}, \mathrm{NaOH}$, or $\mathrm{NaCl}$ aqueous solution. The reaction was maintained at $90^{\circ} \mathrm{C}$ for $4 \mathrm{~h}$ under stirring. The solid-liquid mixture was filtrated afterwards, and the

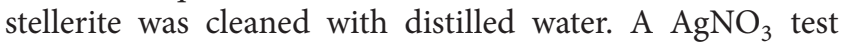
was performed to make sure that no $\mathrm{Cl}^{-}$remained in the stellerite. After grinding, the stellerite was calcinated at $100^{\circ} \mathrm{C}$ for $12 \mathrm{~h}$. These stellerites were denoted as $n \mathrm{AcMS}, n \mathrm{AlMS}$, and $n$ SMS, where $n$ is the concentration of $\mathrm{HCl}, \mathrm{NaOH}$, and $\mathrm{NaCl}$ aqueous solution.

2.1.2. Scanning Electron Microscopy (SEM) Analysis. Morphologies of the fracture surfaces were examined with a scanning electron microscope (SEM S3700, Hitachi, Japan) operating at an accelerating voltage of $10 \mathrm{kV}$. Before observation, the samples were coated with gold using a vacuum sputter-coater.

2.1.3. Fourier Transform Infrared Spectroscopy Analysis. Fourier transform infrared spectroscopy analysis (FTIR) of the samples was carried out in transmission mode using macro techniques $(13 \mathrm{~mm} \Phi$ pellet; $c a .1 .5 \mathrm{mg}$ sample with $350 \mathrm{mg} \mathrm{KBr}$ ). The spectra were recorded with a Nexus Vector spectrometer made by Thermo Nicolet (Nexus 670, Thermo Nicolet Company, USA) under the following specifications: apodization: triangular; detector: $\mathrm{DTGS} / \mathrm{KBr}$; regulation: $4 \mathrm{~cm}^{-1}$; number of scans: 32 .

2.1.4. X-Ray Diffraction Analysis. The X-ray powder diffraction patterns of the samples were recorded on Bruker D8
Advance X-ray diffractometer (step size $0.02^{\circ}, 17.7$ s per step). A generator with $40 \mathrm{kV}$ and current of $40 \mathrm{~mA}$ was employed as a source for $\mathrm{CuK} \alpha$ radiation.

2.1.5. Preparation of Photocatalyst. $\mathrm{TiO}_{2}$ loaded on stellerite was prepared by sol-gel process. The precursor solution composites consist of tetra-n-butyl titanate, pure ethanol, and nitric acid. The nitric acid was used as catalyst to control the hydrolysis process. The detailed steps are as follows: A given amount of tetrabutyl titanate was dissolved in pure ethanol with a volume ratio of $1: 4$ of tetrabutyl titanate to ethanol, and then nitric acid solution was added dropwise into the solution to readjust the $\mathrm{pH}$ value to 4 . Stirring for $20 \mathrm{~min}$, a certain amount of natural stellerite or modified stellerite was added and the ratio of $\mathrm{TiO}_{2}$ : stellerite is $28: 100$. Stirring for $10 \mathrm{~min}$, a certain amount of distilled water was added and the volume ratio of distilled water : nitric acid is $1: 1$. After stirring for $15 \mathrm{~min}$, weak gray sol was obtained and then dried at $100^{\circ} \mathrm{C}$ for $24 \mathrm{~h}$ and at $200^{\circ} \mathrm{C}$ for $4 \mathrm{~h}$ and ground to fine powder in an agate mortar. By this procedure, $\mathrm{TiO}_{2}$ loaded on stellerite was prepared, denoted as $\mathrm{TiO}_{2} /$ stellerite or $n \mathrm{TiO}_{2} / \mathrm{AcMS}$, $n \mathrm{TiO}_{2} / \mathrm{AlMS}$, and $n \mathrm{TiO}_{2} / \mathrm{SMS}$, where $n$ is the concentration of $\mathrm{HCl}, \mathrm{NaOH}$, or $\mathrm{NaCl}$ aqueous solution in the procedure of stellerite modified treatment.

2.1.6. Characterization of Photocatalyst. The effect of stellerite modification on the photocatalytic activity of $\mathrm{TiO}_{2}$ /stellerite photocatalyst was investigated using methyl orange (MO) as the target compound. A total amount of $0.8 \mathrm{~g}$ of photocatalyst was suspended in a $400 \mathrm{~mL}$ of $15 \mathrm{mg} / \mathrm{L}$ MO solution. The suspension was stirred magnetically for $30 \mathrm{~min}$ to reach adsorption equilibrium. The photocatalytic reactions were carried out in a quartz tube irradiated by $365 \mathrm{~nm}$ UV light (light irradiation of $2200 \mu \mathrm{W} / \mathrm{cm}^{2}$ ). The suspensions were withdrawn at intervals and centrifuged at $14,000 \mathrm{rpm}$ for $10 \mathrm{~min}$ and then the residual concentration of MO was determined in solution at $460 \mathrm{~nm}$ using a UV-Vis spectrophotometer (DR5000, HACH, USA). The removal rate of MO was calculated by the following equation:

$$
\eta=\frac{C_{0}-C}{C_{0}}=\frac{A_{0}-A}{A_{0}} \times 100 \%,
$$

where $C_{0}$ and $A_{0}$ are the initial concentration and absorbency of MO solution; $C$ and $A$ are the concentration and absorbency of MO solution after a certain time. Control experiments (direct photolysis) were also carried out without the addition of photocatalyst.

All experiments were run in triplicate with the relative standard deviations (RSD) of about $5 \%$.

\section{Results and Discussion}

3.1. SEM Imaging of Natural and Modified Stellerites. The surface morphology of natural and modified stellerites is shown in Figure 1. It was found that natural stellerite occurs as clear layer shape structure. As a result of $\mathrm{HCl}$ and $\mathrm{NaCl}$ modification, microcracks developed on the surface of stellerite. However, the layer shape structure of stellerite changes 


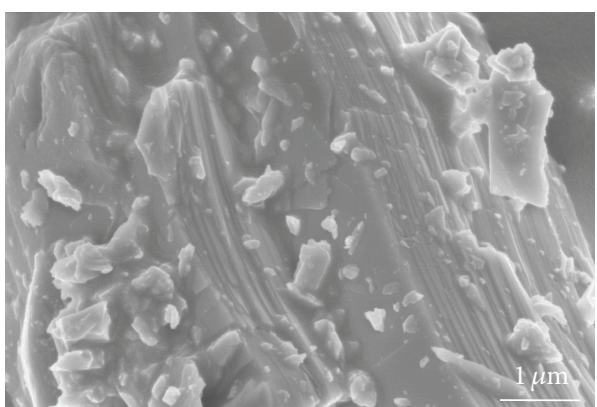

(a)

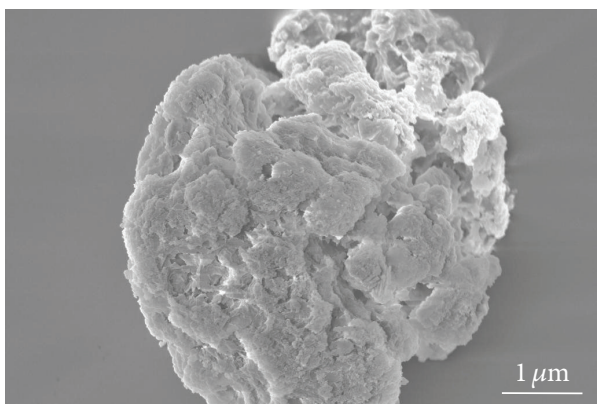

(c)

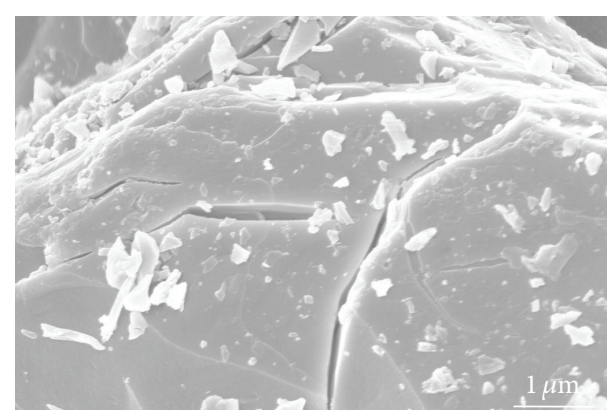

(b)

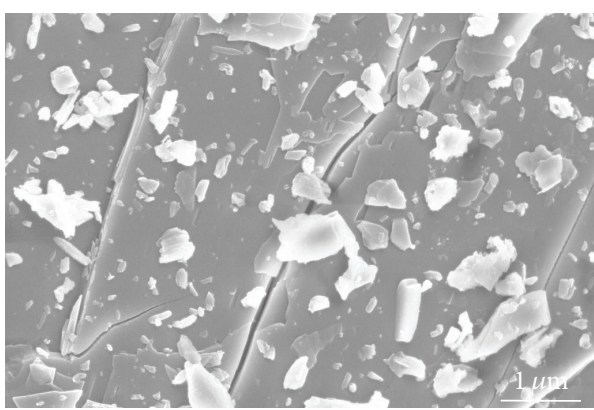

(d)

FIGURE 1: SEM images of natural and modified stellerites: (a) natural stellerite, (b) 1.0AcMS, (c) 0.2AlMS, and (d) 1.0SMS.

to irregular granular structure because of the corrosion by $\mathrm{NaOH}$ solution.

3.2. Si/Al Atomic Ratio. The influence on the $\mathrm{Si} / \mathrm{Al}$ atomic ratios of stellerites by different concentrations of modifying agents is shown in Figure 2. In $\mathrm{HCl}$ modification, the $\mathrm{Si} / \mathrm{Al}$ atomic ratio was raised with the increase of $\mathrm{HCl}$ concentration and 13.86 (surged almost fourfold) of $\mathrm{Si} / \mathrm{Al}$ atomic ratio was obtained by $\mathrm{HCl}$ modification with the concentration of $1.0 \mathrm{~mol} / \mathrm{L}$, indicating that $\mathrm{HCl}$ has a strong dealuminization power correlated with the occurrence of hydroxy nest [12]. The dealuminization reaction can be represented as in Scheme 1.

Instead, the $\mathrm{Si} / \mathrm{Al}$ atomic ratio decreased with the increase in the concentration of $\mathrm{NaOH}$ and $\mathrm{NaCl}$, particularly in $\mathrm{NaOH}$ modification; these results are in accord with previous report [13]. The mechanism of silica dissolution is shown in Scheme 2.

3.3. FTIR Spectra Analysis. The FTIR spectra of natural and modified stellerite samples are shown in Figure 3. The bands at 3480 and $1642 \mathrm{~cm}^{-1}$ were attributed to the valence and bending vibrations of water molecules in stellerite. The peak at $1040 \mathrm{~cm}^{-1}$ indicates the asymmetrical extensional vibrations of $\mathrm{Si}(\mathrm{Al})-\mathrm{O}$. The bands at 795 and $456 \mathrm{~cm}^{-1}$ were due to the symmetric stretching and bending vibrations of $\mathrm{Si}(\mathrm{Al})-\mathrm{O}$.

An obvious shift of the IR vibrations to high frequency for 1.0AcMS in comparison with that of the corresponding natural stellerite sample indicates the dealumination during

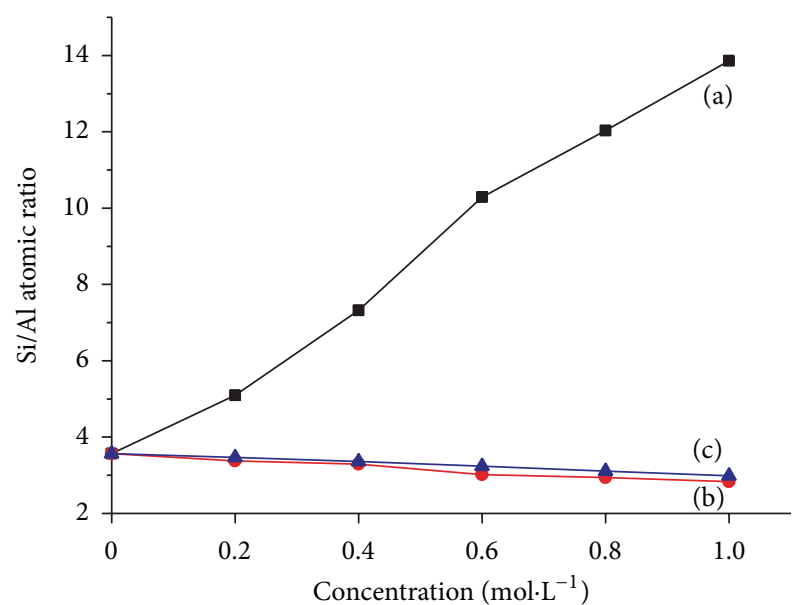

FIGURE 2: $\mathrm{Si} / \mathrm{Al}$ atomic ratios of natural and modified stellerites: (a) $\mathrm{HCl}$ modification, (b) $\mathrm{NaOH}$ modification, and (c) $\mathrm{NaCl}$ modification.

hydrochloric acid modification. The blue shift is particularly obvious for the $\mathrm{Si}(\mathrm{Al})-\mathrm{O}$ intensive asymmetric stretching vibrations at about $1040 \mathrm{~cm}^{-1}$. By contrast, $\mathrm{NaOH}$ modification caused noticeable red shift at $1035 \mathrm{~cm}^{-1}$ in spectra (c) because of the desilication processes (the vibration frequency of $\mathrm{Si}-\mathrm{O}$ is higher than $\mathrm{Al}-\mathrm{O}$ ). Contrary to the spectra of (a) and (d), most band positions did not change following $\mathrm{NaCl}$ modification, suggesting that the base stellerite did not collapse. 


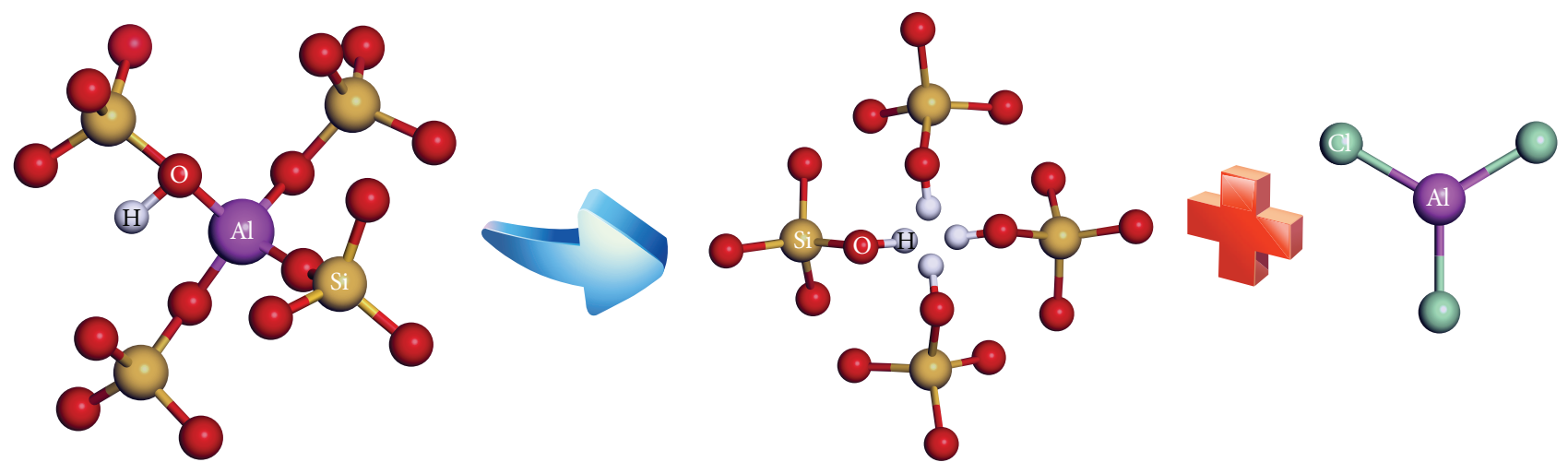

SCHEME 1: Schematic representation of the dealuminization upon treatment in hydrochloric acid.
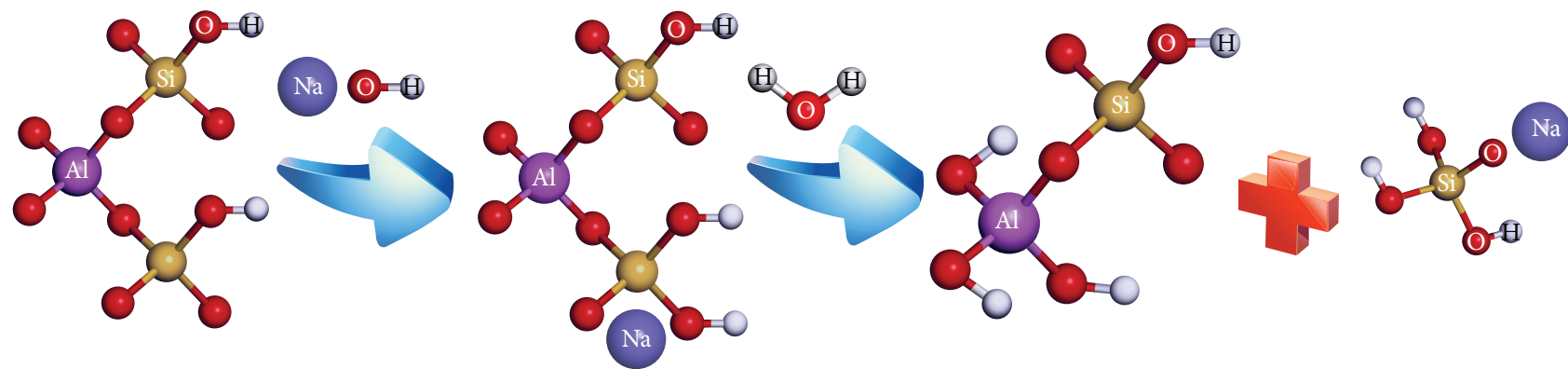

SCHEME 2: Schematic representation of the desilication upon treatment in $\mathrm{NaOH}$ solution.

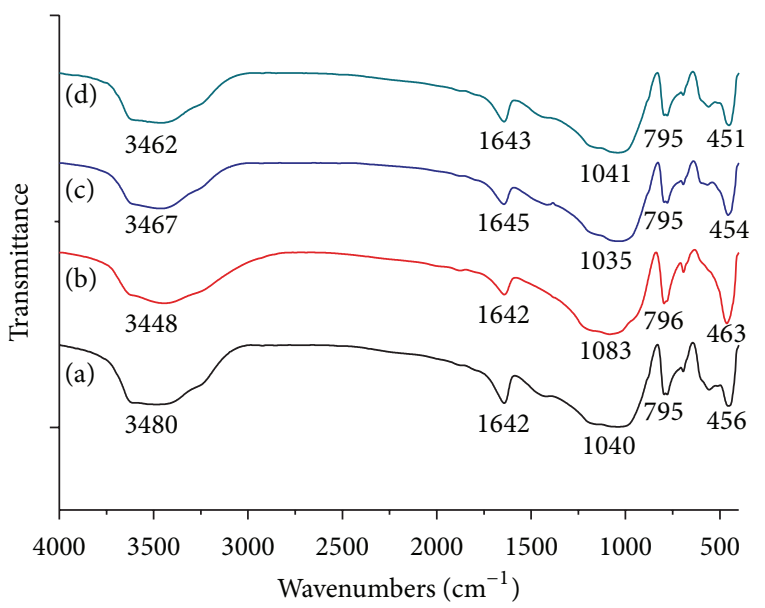

FIGURE 3: FTIR spectra of (a) natural stellerite, (b) 1.0AcMS, (c) $0.2 \mathrm{AlMS}$, and (d) 1.0SMS.

3.4. Structural Analysis. Table 1 presents the parameters of porous structure of various samples. The $S_{\mathrm{BET}}$ value for natural stellerite is $2.2 \mathrm{~m}^{2} / \mathrm{g}$; in the case of treatment of stellerite with $0.4 \mathrm{M} \mathrm{HCl}$, its $S_{\mathrm{BET}}$ value grows to $67.9 \mathrm{~m}^{2} / \mathrm{g}$ and the $V_{\mathrm{BET}}$ value grew by 7 times. Besides, $D_{\mathrm{BET}}$ and $D_{\mathrm{BJH}}$ of the $\mathrm{HCl}$ and $\mathrm{NaCl}$ modified samples are also significantly smaller in comparison with the natural stellerite, indicating the creation of microporous structure. However, $D_{\mathrm{BET}}$ and $D_{\mathrm{BJH}}$ of the $\mathrm{NaOH}$ modified sample grow to 12.7 and $41.0 \mathrm{~nm}$ and reveal that $\mathrm{NaOH}$ modified stellerite can bring about different effect of surface topography compared with $\mathrm{HCl}$ and $\mathrm{NaCl}$ modified stellerite, and this result is consistent with Figure 1.

The adsorption-desorption isotherms for natural and modified stellerite are shown in Figure 4. Based on conventional classification of adsorption, the isotherms of natural and 0.2AlMS can be considered as isotherms of IV type with the hysteresis loop of the type H3. In comparison, the nitrogen adsorption on the $\mathrm{HCl}$ and $\mathrm{NaCl}$ modified stellerite is expressed by I type isotherm with wide hysteresis loop which does not close at low relative pressure. The obvious increases of the micropore volumes of the $\mathrm{HCl}$ and $\mathrm{NaCl}$ modified stellerite are caused by unblocking of the channels of framework structure of stellerite through dealumination during acid modification or ion exchange action during $\mathrm{NaCl}$ modification.

3.5. X-Ray Diffraction Analysis. X-ray examination of the different samples showed (Figure 5) that modifications of stellerite did not damage the stellerite structure that is characterized by the main peaks at $2 \theta$ equal to $9.759^{\circ}$ which can be assigned as $\{020\}$. The characteristic XRD peaks of anatase were observed at $2 \theta=25.352^{\circ}, 37.784^{\circ}, 48.072^{\circ}$, $53.928^{\circ}$, and $55.115^{\circ}$ for $\mathrm{TiO}_{2}$ supported on modified stellerite, which can be assigned as $\{101\},\{004\},\{200\},\{105\}$, and $\{221\}$. No significant rutile peak was found, showing that rutile phase did not form on the surface of stellerite. 
TABLE 1: The parameters of stellerite porous structures by nitrogen adsorption/desorption method.

\begin{tabular}{lccccccc}
\hline \multirow{2}{*}{ Sample } & \multicolumn{3}{c}{ Specific surface area $\left(\mathrm{m}^{2} / \mathrm{g}\right)$} & \multicolumn{2}{c}{ Pore volume $\left(\mathrm{cm}^{3} / \mathrm{g}\right)$} & \multicolumn{2}{c}{ Pore size $(\mathrm{nm})$} \\
& $S_{\mathrm{BET}}$ & $S_{m}$ & $S_{e}$ & $V_{\mathrm{BET}}$ & $V_{\mathrm{BJH}}$ & $D_{\mathrm{BET}}$ & $D_{\mathrm{BJH}}$ \\
\hline Natural & 2.2 & 1.1 & 1.1 & 0.0045 & 0.0096 & 8.2 \\
0.4AcMS & 67.9 & 53.7 & 14.2 & 0.0363 & 0.0088 & 2.1 \\
0.2 AlMS & 18.0 & 1.5 & 16.5 & 0.0570 & 0.1244 & 10.2 \\
1.0SMS & 33.1 & 23.9 & 9.2 & 0.0216 & 0.0154 & 41.0 \\
\hline
\end{tabular}

$S_{m}=S_{\text {t-plot }}$ (micropore area); $S_{e}=S_{\text {t-plot }}$ (external surface area).

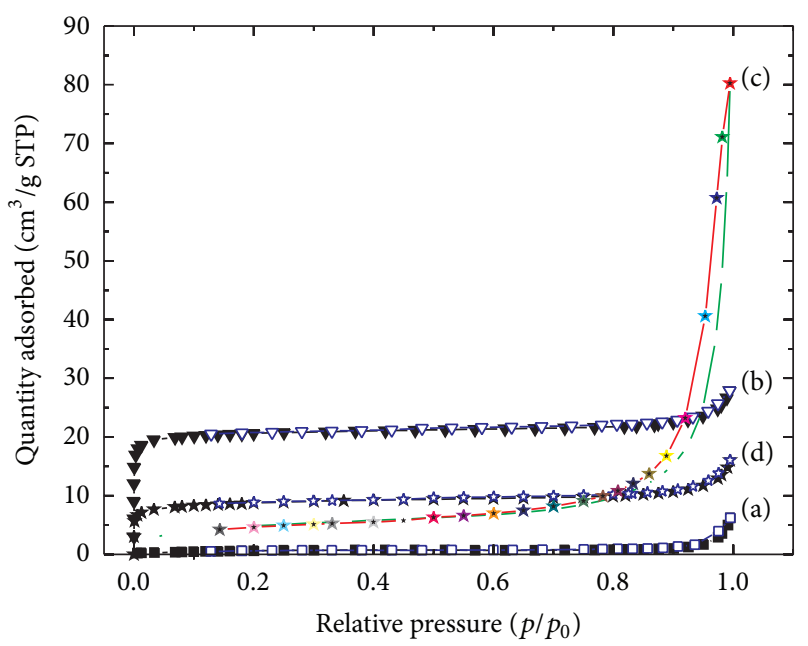

FIgURE 4: Low temperature of adsorption/desorption isotherms of nitrogen on different samples: (a) natural stellerite, (b) 0.4AcMS, (c) 0.2AlMS, and (d) 1.0SMS.

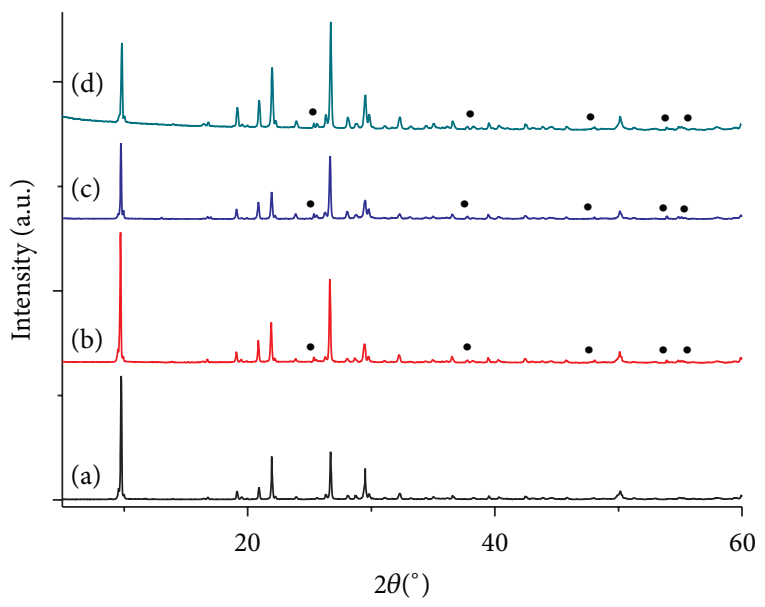

- Anatase

FIGURE 5: XRD patterns of (a) natural stellerite, (b) $0.4 \mathrm{TiO}_{2} / \mathrm{AcMS}$, (c) $0.2 \mathrm{TiO}_{2} / \mathrm{AlMS}$, and (d) $1.0 \mathrm{TiO}_{2} / \mathrm{SMS}$. The ratio of $\mathrm{TiO}_{2}$ : modified stellerite was fixed to $28: 100$.

3.6. Photocatalytic Activity. Figure 6 shows the relationship between $\mathrm{MO}$ degradation and irradiation time for different $\mathrm{TiO}_{2}$ loaded samples at $2 \mathrm{~g} / \mathrm{L}$ of photocatalyst. Photocatalytic activity of natural stellerite was also studied as comparison. It was found that natural stellerite has no photocatalytic

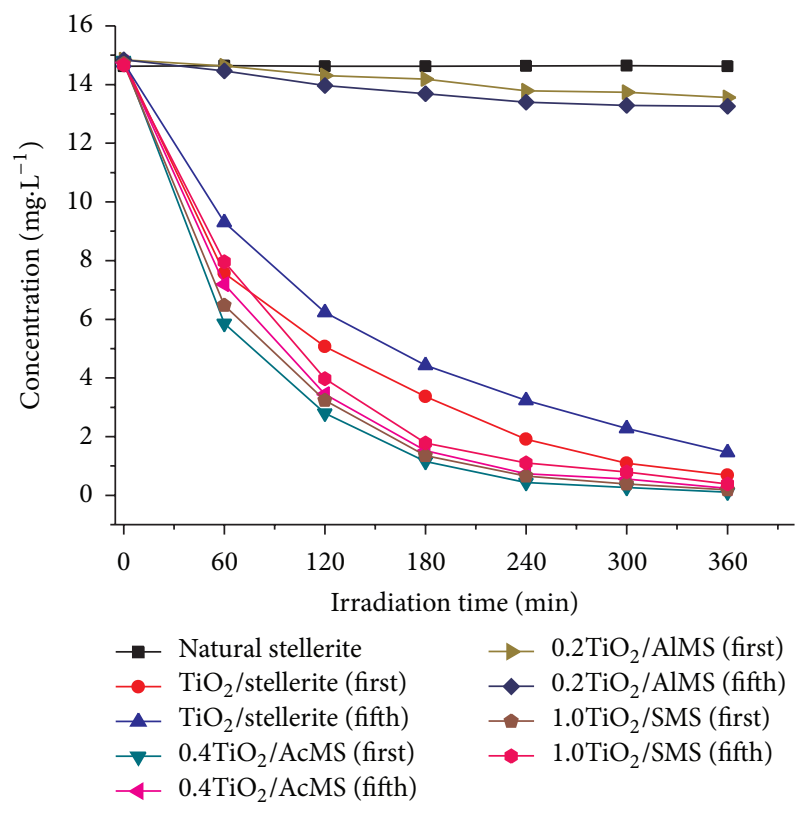

FIGURE 6: MO photocatalytic degradation with prolonged irradiation time.

activity on MO degradation under UV irradiation. MO degradation rates increased with irradiation time using either $\mathrm{TiO}_{2} /$ stellerite or $\mathrm{TiO}_{2}$ load modified stellerite. After $180 \mathrm{~min}$ of irradiation, MO degradation rates were $77.60 \%$, $92.33 \%$, and $91.00 \%$ using $\mathrm{TiO}_{2} /$ stellerite, $0.4 \mathrm{TiO}_{2} / \mathrm{AcMS}$, and $1.0 \mathrm{TiO}_{2} / \mathrm{SMS}$ as photocatalyst. The results show that photocatalytic activity of $\mathrm{TiO}_{2}$ is improved by $\mathrm{HCl}$ and $\mathrm{NaCl}$ modification of stellerite. The photocatalyst was recycled after filtration and heating treatment at $100^{\circ} \mathrm{C}$ for $12 \mathrm{~h}$ and $200^{\circ} \mathrm{C}$ for $2 \mathrm{~h}$ in every cycle. After four cycles, MO orange degradation rates decreased from $77.60 \%, 92.33 \%$, and $91.00 \%$ to $70.47 \%, 89.86 \%$, and $88.13 \%$, respectively. The slight decrease of photocatalytic activity was due to $\mathrm{TiO}_{2}$ loss from the surface of stellerite and the fouling of the photocatalyst by byproducts during degradation.

On the contrary, the photocatalytic activity of $0.2 \mathrm{TiO}_{2} / \mathrm{AlMS}$ was also disappeared due to the follow reasons: First, the porous structure of stellerite was damaged to some extent by $\mathrm{NaOH}$; second, the photocatalysts agglomerate together to form larger clusters due to the viscous silicates; third, the transparency of the solution was decreased by silicates. 


\section{Conclusions}

(1) $\mathrm{TiO}_{2}$ was dispersed using sol-gel method on the surfaces of stellerite treated by $\mathrm{HCl}, \mathrm{NaOH}$, or $\mathrm{NaCl}$.

(2) The $S_{\text {BET }}$ value of stellerite was increased by modification. $D_{\mathrm{BET}}$ of natural stellerite, $0.4 \mathrm{AcMS}, 0.2 \mathrm{AlMS}$, and 1.0SMS was $8.2,2.1,12.7$, and $2.6 \mathrm{~nm}$, respectively. $\mathrm{HCl}$ and $\mathrm{NaCl}$ modification stimulate the production of micropores, and the surface of stellerite appeared to dissolve by $\mathrm{NaOH}$ modification.

(3) The photocatalytic activity of $0.4 \mathrm{TiO}_{2} / \mathrm{AcMS}$ and $1.0 \mathrm{TiO}_{2} / \mathrm{SMS}$ was better than that of natural stellerite. The composite photocatalyst had excellent photocatalytic activity after four recycles.

\section{Conflict of Interests}

The authors declare that there is no conflict of interests regarding the publication of this paper.

\section{Acknowledgments}

The authors would like to acknowledge support from the Key Projects in the National Science \& Technology Pillar Program during the Twelfth Five-year Plan Period (Grant no. 2013BAC16B04).

\section{References}

[1] Y. Tian, H. Li, L. P. Li et al., "In-situ integration of microbial fuel cell with hollow-fiber membrane bioreactor for wastewater treatment and membrane fouling mitigation," Biosensors \& Bioelectronics, vol. 64, pp. 189-195, 2015.

[2] A. G. D. Prasad and M. A. Abdullah, "Biosorption of $\mathrm{Cr}(\mathrm{VI})$ from synthetic wastewater using the fruit shell of gulmohar (delonix regia): application to electroplating wastewater," BioResources, vol. 5, no. 2, pp. 838-853, 2010.

[3] D. Pokhrel and T. Viraraghavan, "Treatment of pulp and paper mill wastewater-a review," Science of the Total Environment, vol. 333, no. 1-3, pp. 37-58, 2004.

[4] Ö. Kerkez and İ. Boz, "Photodegradation of methylene blue with $\mathrm{Ag}_{2} \mathrm{O} / \mathrm{TiO}_{2}$ under visible light: operational parameters," Chemical Engineering Communications, vol. 202, no. 4, pp. 534541, 2015.

[5] N. Mahmoud, T. Ahmed, O. Shinichi, and S. Masaaki, "Biological hydrogen production from starch wastewater using a novel up-flow anaerobic staged reactor," BioResources, vol. 8, no. 4, pp. 4951-4968, 2013.

[6] M. Pérez, F. Torrades, J. Peral et al., "Multivariate approach to photocatalytic degradation of a cellulose bleaching effluent," Applied Catalysis B: Environmental, vol. 33, no. 2, pp. 89-96, 2001.

[7] L. Chen and B. Yan, "Multi-color luminescence of hybrids based with lanthanide functionalized zeolite A and titania," Colloid and Polymer Science, vol. 293, no. 6, pp. 1847-1853, 2015.

[8] M. R. Espino-Estévez, C. Fernández-Rodríguez, O. M. González-Díaz, J. A. Navío, D. Fernández-Hevia, and J. M. Doña-Rodríguez, "Enhancement of stability and photoactivity of $\mathrm{TiO}_{2}$ coatings on annular glass reactors to remove emerging pollutants from waters," Chemical Engineering Journal, vol. 279, pp. 488-497, 2015.

[9] D. C. L. Vasconcelos, E. H. M. Nunes, A. C. S. Sabioni, P. M. P. Vasconcelos, and W. L. Vasconcelos, "Optical characterization of 316L stainless steel coated with sol-gel titania," Journal of NonCrystalline Solids, vol. 358, no. 22, pp. 3042-3047, 2012.

[10] Z. H. Gao, Z. D. Cui, S. L. Zhu, Y. Q. Liang, Z. Y. Li, and X. J. Yang, "Design and synthesis of $\mathrm{MWNTs}^{-\mathrm{TiO}_{2}}$ nanotube hybrid electrode and its supercapacitance performance," Journal of Power Sources, vol. 283, pp. 397-407, 2015.

[11] A. J. Wang, W. Yu, Y. Fang et al., "Facile hydrothermal synthesis and optical limiting properties of $\mathrm{TiO}_{2}$-reduced graphene oxide nanocomposites," Carbon, vol. 89, pp. 130-141, 2012.

[12] M.-C. Silaghi, C. Chizallet, and P. Raybaud, "Challenges on molecular aspects of dealumination and desilication of zeolites," Microporous and Mesoporous Materials, vol. 191, pp. 82-96, 2014.

[13] Z. Liang and J. R. Ni, "Improving the ammonium ion uptake onto natural zeolite by using an integrated modification process," Journal of Hazardous Materials, vol. 166, no. 1, pp. 52-60, 2009. 

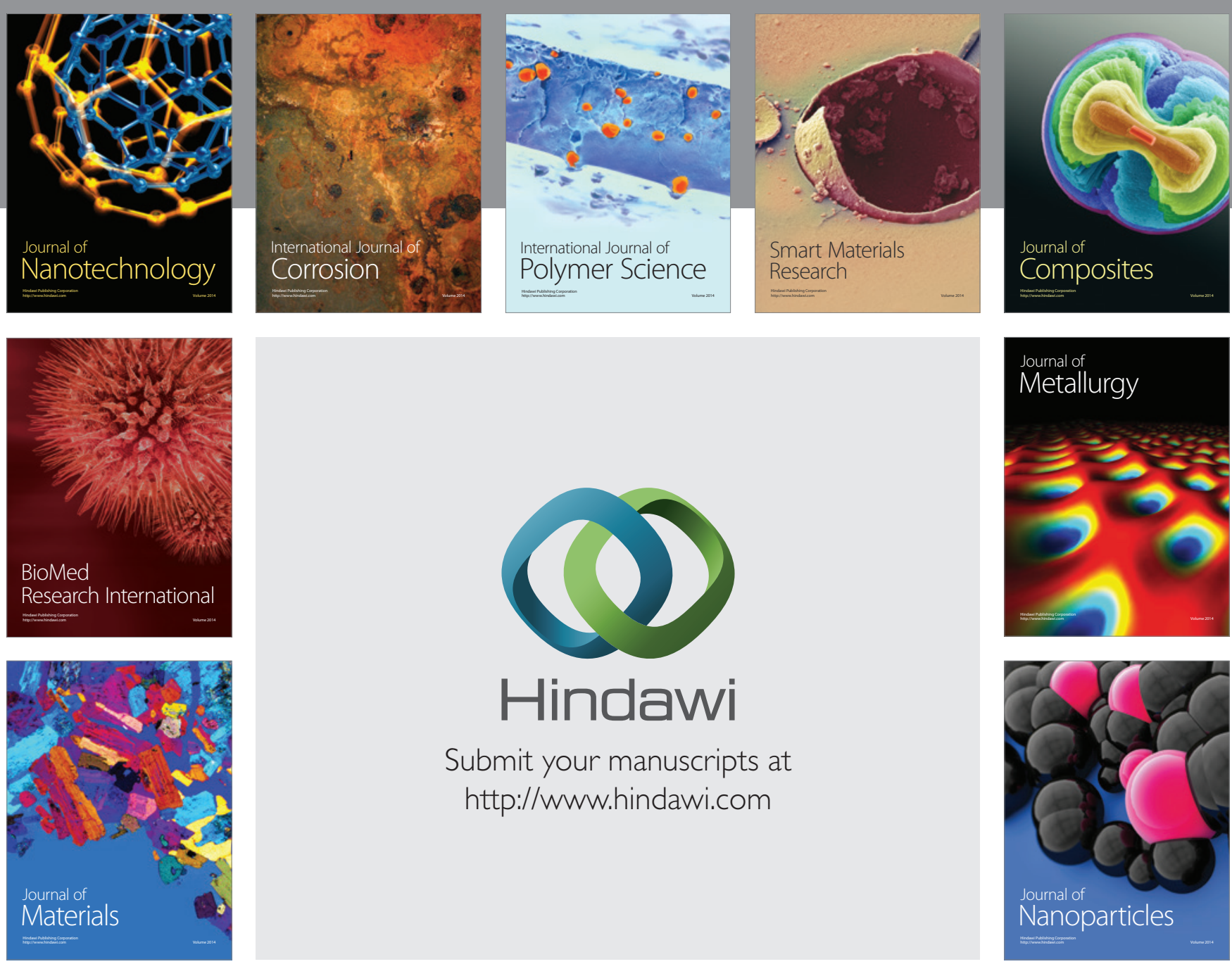

Submit your manuscripts at http://www.hindawi.com
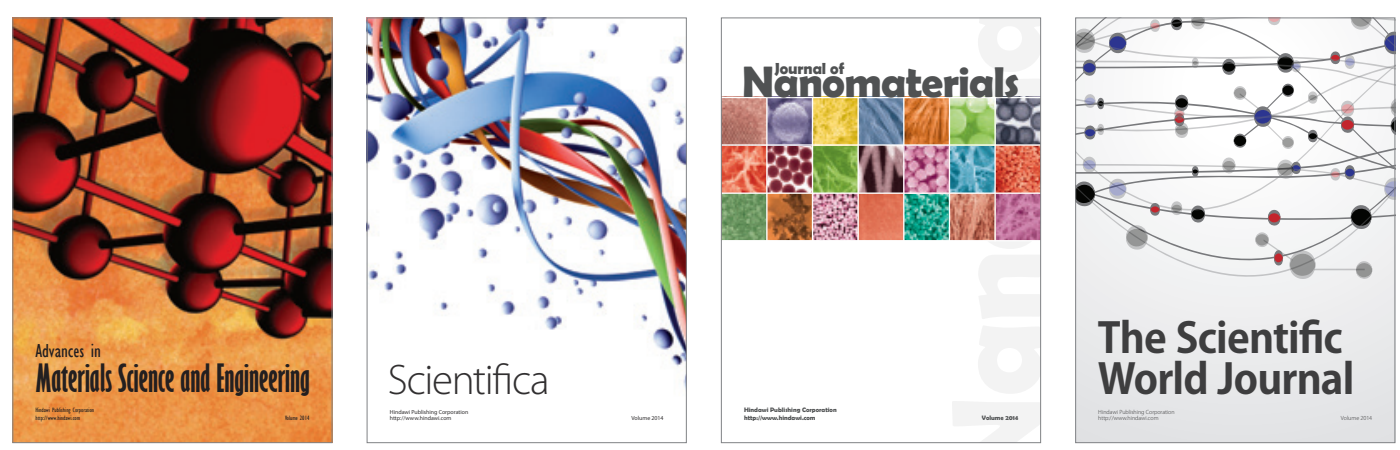

\section{The Scientific World Journal}
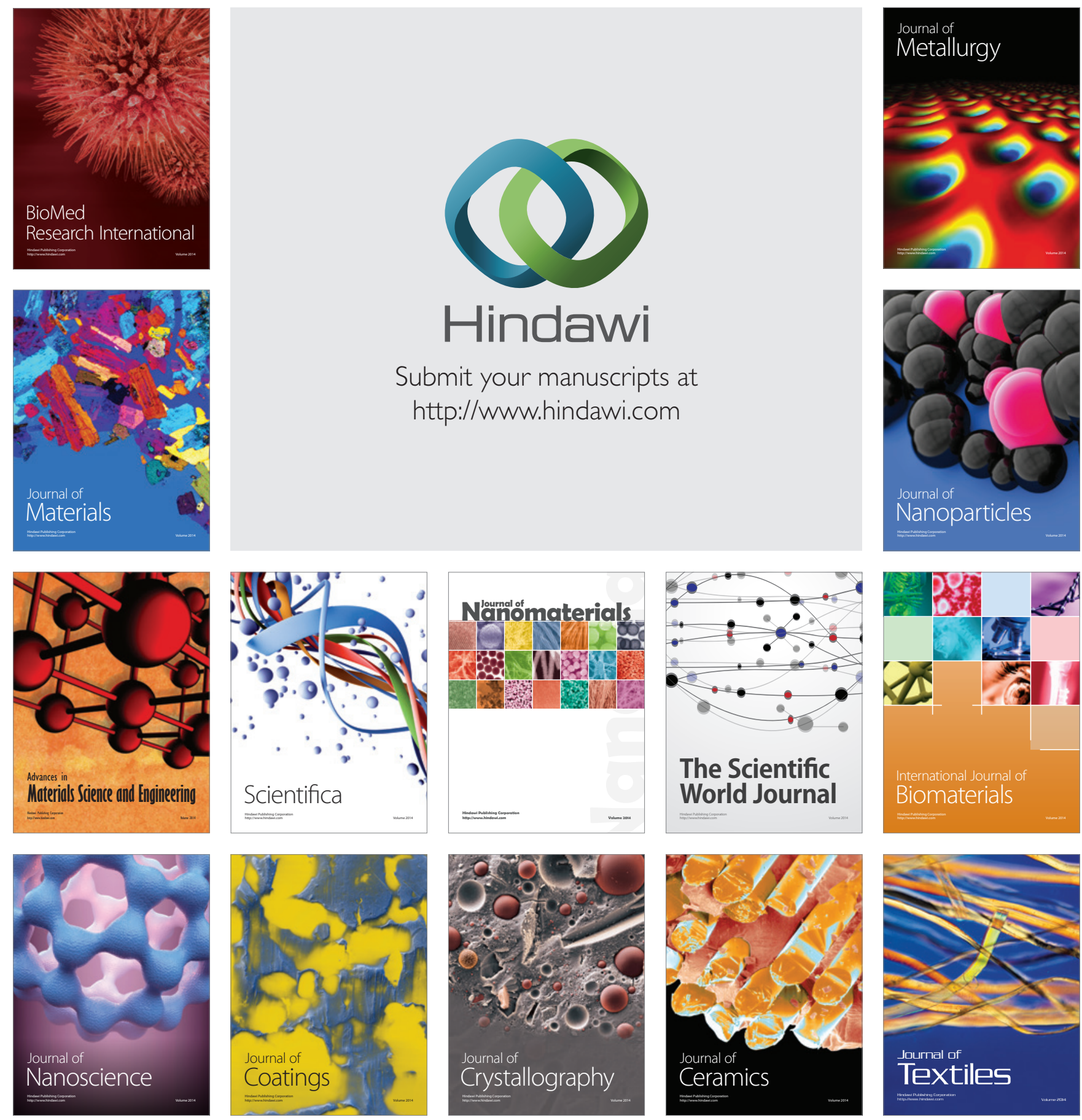